\title{
Thoracic endovascular aortic repair: A single center's 15-year experience
}

\author{
Vincent Ziza, MD, ${ }^{\mathrm{a}}$ Ludovic Canaud, MD, PhD, ${ }^{\mathrm{a}}$ Nicolas Molinari, PhD, ${ }^{\mathrm{b}}$ Pascal Branchereau, MD, \\ Charles Marty-Ané, $\mathrm{MD}, \mathrm{PhD},{ }^{\mathrm{a}}$ and Pierre Alric, $\mathrm{MD}, \mathrm{PhD}^{\mathrm{a}}$
}

\section{ABSTRACT}

Objective: Specific complications of thoracic endovascular aortic repair (TEVAR) exist and long-term data are lacking. The purpose of this study was to evaluate our long-term TEVAR results.

Methods: This is a single-center retrospective study of 223 patients undergoing TEVAR from 1998 to 2013. Indication was aneurysm (45\%), traumatic $(26 \%)$, dissection $(23 \%)$, and septic $(6 \%)$.

Results: Patients' mean age was $62.7 \pm 17.9$ years, $84 \%$ of them had an American Society of Anesthesiologists score $\geq 3$, and $42 \%$ had an aortic rupture. TEVAR was performed in zone $0(n=17), 1(n=17)$, or $2(n=59)$ in $42 \%$ of patients. Technical success rate was $96.4 \%$. Overall 30 -day mortality was $11.7 \%$ (elective aneurysm, $11.6 \%$; emergent aneurysm, $34.3 \%$; acute type B dissection, $14.8 \%$; chronic dissection, $4.2 \%$; septic, $8.3 \%$; and traumatic, $1.7 \%$ ). Major adverse events included stroke in $4.5 \%$, spinal cord ischemia in $1.8 \%$, and retrograde aortic dissection in $2.7 \%$. Mean follow-up was $43.4 \pm 38$ months. Estimated aortic complications-free survivals at $12,36,60$, and 120 months were ( $\% \pm$ standard error) $73 \% \pm 3 \%, 64 \% \pm 4 \%, 62 \% \pm 4 \%$ and $57 \% \pm 5 \%$, respectively. Multivariate analysis showed that patients treated for a chronic aortic dissection had a significant risk of late reintervention $(P=.001)$

Conclusions: Because of its simplicity and low morbimortality rate, TEVAR has become the first-line approach for thoracic aortic diseases. Mortality outcomes are related to aortic pathology, emergent status, and proximal landing zone. To improve long-term results, rigorous patient selection and follow-up, development of referral centers, and technologic evolution of materials have to be reached. (J Thorac Cardiovasc Surg 2016;151:1595-603)

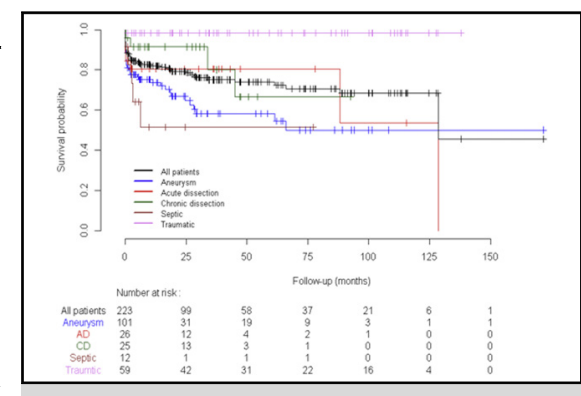

Product-limit survival estimates curves.

\section{Central Message}

We present a single-institution's experience with early and late outcomes of TEVAR across 15 years

\section{Perspective}

Mortality outcomes after thoracic endovascular aortic repair are related to the aortic pathology, elective or emergent status, and proximal landing zone. To improve long-term results, rigorous patient selection and follow-up, development of referral centers, and technologic evolution of materials have to be reached.

See Editorial Commentary page 1604.
Since its first description in $1994,{ }^{1}$ thoracic endovascular aortic repair (TEVAR) has evolved from homemade experimental devices to being the first-line therapy for most thoracic aortic pathologies using commercially available thoracic stent-grafts for anatomically suitable patients. . $^{2,3}$

Experience with abdominal aortas showed that the early mortality advantage associated with endovascular repair of abdominal aneurysms was affected by specific reported complications, such as late aortic rupture and endoleaks. ${ }^{4}$

\footnotetext{
From the Departments of ${ }^{\mathrm{a}}$ Vascular and Thoracic Surgery and ${ }^{\mathrm{b}}$ Clinical Research and Epidemiology, Arnaud de Villeneuve University Hospital, Montpellier, France. Received for publication April 13, 2015; revisions received Nov 22, 2015; accepted for publication Dec 12, 2015; available ahead of print Jan 29, 2016.

Address for reprints: Vincent Ziza, MD, Service de Chirurgie Thoracique et Vasculaire, Hôpital Arnaud de Villeneuve, CHU de Montpellier, 191 ave Doyen Gaston Giraud, 34090 Montpellier, France (E-mail: vziza@club.fr). $0022-5223 / \$ 36.00$

Copyright (C) 2016 by The American Association for Thoracic Surgery http://dx.doi.org/10.1016/j.jtcvs.2015.12.030
}

Similar long-term durability issues concerning TEVAR have been raised. Furthermore, encouraging results of TEVAR have prompted many authors to use stent-grafts in more challenging anatomical regions using a hybrid approach, ${ }^{5-8}$ increasing the risk of TEVAR failure.

Most studies describe early outcomes from TEVAR with relatively short-term follow-up. ${ }^{9-17}$ We present the early and late outcomes of our single-institution experience with TEVAR.

Scanning this QR code will take you to supplemental figures and tables for this article.

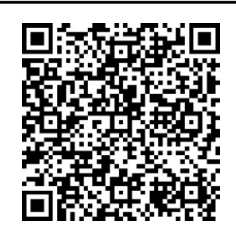




\section{Abbreviations and Acronyms \\ ASA = American Society of Anesthesiologists \\ CT = celiac trunk \\ LSA = left subclavian artery \\ MSOF $=$ multisystem organ failure \\ RAD = retrograde aortic dissection \\ SAV = supra-aortic vessels \\ SCI = spinal cord ischemia \\ SMA = superior mesenteric artery \\ TEVAR $=$ thoracic endovascular aortic repair}

\section{MATERIALS AND METHODS \\ Patients}

From November 1998 to January 2013, 235 patients were treated in our institution for various thoracic aortic pathologies. Among these patients, $223 \mathrm{had}$ favorable preoperative anatomic conditions to perform TEVAR. They constituted the basis of our study. A retrospective analysis of this series was performed using a prospectively maintained database. Patients were divided into 4 groups (aneurysm, dissection, traumatic, and septic).

All patients underwent a preoperative computed tomography scan to assess the feasibility of TEVAR. As a prerequisite for successful stent-graft placement, a proximal landing zone of healthy and nondissected aorta (or graft) of at least $20 \mathrm{~mm}$ and a diameter $<40 \mathrm{~mm}$ were deemed necessary. Our criteria for oversizing have changed with time. At the beginning of our experience, the goal of TEVAR was to achieve lesion exclusion and we used a $20 \%$ oversizing for all the different diseases. Furthermore, at the beginning of our experience, the range of stent-graft diameter available was limited when compared with the broad range of stent-graft diameters currently available. However, complications related to excessive oversizing such as stent-graft collapse and $\mathrm{RAD}$ have prompted us to change our surgical strategy. Oversizing is currently moderate (maximum, 15\%) and depends on the disease: $10 \%$ to $15 \%$ for traumatic transection and degenerative aneurysm, 10\% for chronic aortic dissection, and $5 \%$ for acute aortic dissection.

According to the classification proposed by Fillinger and colleagues ${ }^{18}$ patients were divided into 5 groups based to the proximal landing zone (Figure E1).

Study protocols were in accordance with the Declaration of Helsinki and were approved by the Montpellier Institutional Review Board.

\section{Procedure}

In case of pathologies involving the aortic arch, successful stent-graft placement required supra-aortic vessel (SAV) debranching before stentgraft deployment to achieve a suitable proximal landing zone. Technical details of SAV debranching have been described in previous publications. ${ }^{7,8,19}$ In case of staged procedure, 1 week was observed between debranching and TEVAR. Prophylactic use of cerebrospinal fluid drainage to prevent spinal cord ischemia (SCI) was not used.

In cases where overstenting of the origin of the left subclavian artery (LSA) was necessary, revascularization was systematic in elective cases and in emergent patients without unstable hemodynamic status at the time of treatment.

In a few cases, overstenting of the celiac aorta was deemed necessary. Visceral debranching was performed via a prosthetic bypass from the aorta or iliac artery to the celiac trunk (CT), superio ${ }^{\mathrm{r}}$ mesenteric artery (SMA), and/or renal arteries.

After achieving suitable landing zones, endograft deployment was performed. Technical details on endograft deployment have been described in previous publications. ${ }^{7,8,19}$ After deployment, stent-graft modeling with a low-pressure balloon was performed, except in dissection cases.
Outcome criteria were defined according to the Reporting Standards for Thoracic Endovascular Aortic Repair. ${ }^{18}$ Technical success required successful introduction and successful deployment of the device in the absence of surgical conversion to open repair, death $\leq 24$ hours, type I or III endoleaks as evidenced by procedural angiography, or graft obstruction. Followup included clinical examination and computed tomography scans during hospital stay, at 1 month, 6 months, and yearly thereafter.

\section{Statistics}

Primary research concerned all patients and pathology outcomes. Pathology-specific mortality analyses were presented as secondary objectives without adjusted $P$ value for multiple comparisons.

Descriptive data were summarized as mean \pm standard deviation or median with interquartile range according to the normality of the distribution, assessed with the Shapiro-Wilk test and compared with Mann-Whitney $U$ or $t$ test. Categorical data were expressed as number and percentages and compared with a $\chi^{2}$ analysis.

Early outcome data were analyzed using logistic regression after calibration using the Hosmer-Lemeshow goodness-of-fit test. Late outcome is a time-related data point and was analyzed using a Cox regression model. Every variable associated with a $P$ value below .20 in the univariate analysis was entered into multivariate models. A stepwise procedure was used to obtain the final multivariate model.

Survival status was assessed by the Kaplan-Meier method and compared between groups with the log-rank test.

Statistical analysis was performed using R Software version 3.1.0 (R Foundation for Statistical Computing, Vienna, Austria).

\section{RESULTS}

We performed 223 thoracic aortic stent-grafting procedures from November 1998 to January 2013. The number of patients treated in each calendar year is reported in Figure E2. A total of 280 endografts were deployed (Table E1). There was no evidence for propensity for certain types of grafts for certain pathologies or zones. Patient demographic data are described in Table E2.

Distribution of pathologies treated included aneurysm group $(\mathrm{n}=101 ; 45 \%)$, traumatic transections $(\mathrm{n}=59$; $26 \%)$, acute and chronic dissections $(\mathrm{n}=51 ; 23 \%)$, and septic pathologies $(\mathrm{n}=12 ; 5 \%)$. Procedure was emergent in 121 patients (54\%), including 93 aortic ruptures (42\%); 102 (46\%) procedures were elective.

In the aneurysm group, there were 87 degenerative aneurysms, 9 anastomotic pseudoaneurysms, and 5 penetrating ulcers. Thirty-two procedures were emergent, including 24 aortic ruptures.

In the dissection group, there were 25 chronic dissections (including 1 aortic rupture) and 26 type B acute dissections with 8 aortic ruptures, 5 malperfusions, 7 patients with best medical treatment having rapid aortic expansion, and 6 uncomplicated patients included in the Acute Dissection: Stent Graft or Best Medical Therapy (ADSORB) study. ${ }^{20}$

In the traumatic group, diagnosis of aortic disruption was achieved at initial admission for 50 patients. Thirty-three $(56 \%)$ had TEVAR procedure during the first 24 hours. The delay between the time of aortic disruption and endovascular treatment was $<5$ days for $82 \%$ of patients with a mean interval of $4.1 \pm 8.8$ days. For 6 patients, treatment was delayed due to septic state or major cerebral lesions. 
TABLE 1. Distribution of proximal landing zone

\begin{tabular}{|c|c|c|c|c|c|}
\hline Zone & $\begin{array}{c}\text { Total } \\
(\mathrm{n}=\mathbf{2 2 3}) \\
\end{array}$ & $\begin{array}{c}\text { Aneurysm group } \\
\quad(\mathbf{n}=\mathbf{1 0 1}) \\
\end{array}$ & $\begin{array}{l}\text { Dissection group } \\
\quad(\mathbf{n}=\mathbf{5 1}) \\
\end{array}$ & $\begin{array}{c}\text { Traumatic group } \\
(\mathbf{n}=\mathbf{5 9})\end{array}$ & $\begin{array}{l}\text { Septic group } \\
\quad(\mathbf{n}=12)\end{array}$ \\
\hline Zone 0 & $17(8)$ & $10(9.9)$ & $6(11.8)$ & $0(0)$ & $1(8.3)$ \\
\hline Emergent & $6(2.7)$ & $3(3.0)$ & $2(3.9)$ & $0(0)$ & $1(8.3)$ \\
\hline Elective & $11(4.9)$ & $7(6.9)$ & $4(7.8)$ & $0(0)$ & $0(0)$ \\
\hline Zone 1 & $17(8)$ & $10(9.9)$ & $3(5.9)$ & $1(1.7)$ & $3(25)$ \\
\hline Emergent & $6(2.7)$ & $1(1.0)$ & $1(2.0)$ & $1(1.7)$ & $3(25)$ \\
\hline Elective & $11(4.9)$ & $9(8.9)$ & $2(3.9)$ & $0(0)$ & $0(0)$ \\
\hline Zone 2 & $59(26)$ & $24(23.8)$ & $17(33.3)$ & $15(25.4)$ & $3(25)$ \\
\hline Emergent & 29 (13) & $6(5.9)$ & $10(19.6)$ & $10(16.9)$ & $3(25)$ \\
\hline Elective & $30(13.4)$ & $18(17.8)$ & 7 (13.7) & $5(8.5)$ & $0(0)$ \\
\hline Zone 3 & $81(36)$ & $21(20.8)$ & $18(35.3)$ & $41(69.5)$ & $1(8.3)$ \\
\hline Emergent & $63(28.2)$ & $13(12.9)$ & $12(23.5)$ & $37(62.7)$ & $1(8.3)$ \\
\hline Elective & $18(8.1)$ & $8(7.9)$ & $6(11.8)$ & $4(6.8)$ & $0(0)$ \\
\hline Zone 4 & $33(15)$ & $26(25.7)$ & $4(7.8)$ & $0(0)$ & $3(25)$ \\
\hline Emergent & $11(4.9)$ & 7 (6.9) & $1(2.0)$ & $0(0)$ & $3(25)$ \\
\hline Elective & $22(9.9)$ & $19(18.8)$ & $3(5.9)$ & $0(0)$ & $0(0)$ \\
\hline Zone 5 & $16(7)$ & $10(9.9)$ & $3(5.9)$ & $2(3.4)$ & $1(8.3)$ \\
\hline Emergent & $6(2.7)$ & $2(2.0)$ & $1(2.0)$ & $2(3.4)$ & $1(8.3)$ \\
\hline Elective & $10(4.5)$ & $8(7.9)$ & $2(3.9)$ & $0(0)$ & $0(0)$ \\
\hline
\end{tabular}

Values are presented as $\mathrm{n}(\%)$.

Nine patients had their aortic disruption discovered later after initial traumatism. These patients underwent an elective procedure.

In the septic group, there were 4 septic pseudoaneurysms, 3 aortobronchials fistulas, and 2 aortoesophageal fistulas. All these procedures were emergent with 11 aortic ruptures.

Distribution of proximal landing zones is shown in Table 1 and distal landing zones in Table E3.

For Zone 0, SAV debranching and endograft deployment was performed as a single-stage procedure for 13 patients. Five patients had only brachiocephalic trunk and left common carotid artery revascularizations.

For Zone 1, 16 patients had revascularizations of the left common carotid artery and of the LSA. Only 1 patient underwent a staged procedure.

For Zone 2, 20 patients had an LSA covering without revascularization. Revascularization was performed as a staged procedure in 5 cases.

Eight patients $(3.6 \%)$ required coverage of the visceral trunks: 2 patients had CT coverage without prior revascularization and 6 patients underwent a single stage procedure with 4 revascularizations of both CT and SMA ( 2 patients also underwent renal bypass), 1 revascularization of the $\mathrm{CT}$, and 1 revascularization of the SMA.

The mean number of stent-grafts per case was $1.25 \pm 0.25$ (range, 1-4). Mean stent-graft diameter was $34.8 \pm 5.7 \mathrm{~mm}$ and mean aortic length covering was $168.0 \pm 79.2 \mathrm{~mm}$ (range, $55-500 \mathrm{~mm}$ ). Access locations included common femoral artery (211 patients; 94.6\%), common iliac artery ( 8 cases; $3.6 \%$ ), and abdominal aorta ( 4 cases; $1.8 \%$ ). There were no intraoperative surgical conversions.

\section{Intraoperative Complications}

Intraoperative mortality was $1.3 \%$. Three patients treated for a ruptured aortic aneurysm in zone 3 had a fatal cardiac evolution during TEVAR. Nonfatal complications are reported in Table E4. Multivariate analysis (Table 2) showed that the statistically significant factor of stent-graft migration in the cohort was the use of the TAG or C-Tag device (Gore Medical, Flagstaff, Ariz) $(P=.02)$. There was trend toward a higher migration rate in patients who underwent TEVAR in zone 0,1 , or $2(P=.06)$.

\section{Early Outcome}

Stroke, SCI, and death were reported for elective and nonelective TEVAR with respect to pathology and proximal landing zone (Table 3). Overall 30-day mortality was $11.7 \%$ (12.6\% during the first half of the study, compared with a $10.8 \%$ 30-day mortality during the second half; $P=.83$ ). Multivariate analysis showed that the statistically significant factor of stroke was patients treated for an acute type $\mathrm{B}$ aortic dissection $(P=.03)$ (Table 2$)$.

Technical success was $96.9 \%$ (216 patients). Technical failures were related to 3 intraoperative deaths (cardiac related) and 4 deaths during the first postoperative day (1 ruptured degenerative aneurysm in zone 3 , 1 elective degenerative aneurysm in zone 3,1 type $\mathrm{B}$ acute aortic dissection in zone 2, and 1 aortobronchial fistulae).

There were important differences in the pathologyspecific mortality. Aneurysm group mortality $(18.8 \%)$ and traumatic group mortality $(1.7 \%)$ were significantly different $(P<.01)$. Comparison with dissection group mortality $(9.8 \%)$ or septic group mortality did not disclose any 
TABLE 2. Multivariate logistic regression analysis for predictors of early and long-term outcomes data

\begin{tabular}{|c|c|c|c|}
\hline Variable & $\begin{array}{c}\text { Hazard } \\
\text { ratio }\end{array}$ & $\begin{array}{c}95 \% \text { Confidence } \\
\text { interval } \\
\end{array}$ & $\begin{array}{c}P \\
\text { value }\end{array}$ \\
\hline \multicolumn{4}{|l|}{ Device migration } \\
\hline Tag or C-Tag* & 23.78 & $1.43-396.46$ & .03 \\
\hline Proximal landing zone 0,1 , or 2 & 2.73 & $0.95-7.89$ & .06 \\
\hline \multicolumn{4}{|l|}{ Death } \\
\hline Dialysis & 10.13 & $1.27-80.63$ & .03 \\
\hline $\begin{array}{l}\text { Chronic obstructive pulmonary } \\
\text { disease }\end{array}$ & 7.18 & $2.45-21.08$ & $<.01$ \\
\hline Emergent & 4.44 & $1.53-12.90$ & $<.01$ \\
\hline \multicolumn{4}{|l|}{ Stroke } \\
\hline Acute dissection & 25.36 & $1.52-422.68$ & .03 \\
\hline \multicolumn{4}{|l|}{ Retrograde aortic dissection } \\
\hline Proximal landing zone 0 or 1 & 16.35 & $3.20-83.44$ & $<.01$ \\
\hline \multicolumn{4}{|l|}{ Early reintervention } \\
\hline Proximal landing zone 0 or 1 & 7.10 & $2.42-20.79$ & $<.01$ \\
\hline \multicolumn{4}{|l|}{ Late reintervention } \\
\hline Chronic dissection & 8.96 & $1.67-47.99$ & .01 \\
\hline \multicolumn{4}{|l|}{ Endoleak } \\
\hline Proximal landing zone 5 & 0.09 & $0.01-1.10$ & .07 \\
\hline \multicolumn{4}{|l|}{ Major endoleak (Type I or III) } \\
\hline Zenith TX $2 \nmid$ device & 12.25 & $0.97-154.79$ & .05 \\
\hline
\end{tabular}

significant differences. For the aneurysm group, the mortality rate was significantly higher for pathologies requiring emergent $(34.4 \%)$ interventions compared with elective procedures $(11.6 \%)(P=.006)$. Postoperative causes of deaths are detailed in Table E5. With a 5.4\% rate, multisystem organ failure (MSOF) was the principal cause of perioperative death. Statistical analysis could not demonstrate any significant risk factor for MSOF, but dialysis $(P=.03)$, chronic obstructive pulmonary disease $(P<.01)$, and emergent procedure $(P<.01)$ were demonstrated as predictive factors for perioperative death (Table 2).

The median length of stay was 9 days (range, 1108 days). Overall, $72 \%$ of patients underwent TEVAR without any complication or secondary intervention (Tables E6 and E7). Multivariate analysis showed that TEVAR procedure performed in zone 0 or 1 was the only predictive factor of early reintervention $(P<.001)$ (Table 2$)$.

\section{Late Outcome}

The median follow-up period was 29.9 months (range, 1.25-171.8). At 12, 36, and 60 months, follow-up was completed for $74 \%, 56 \%$, and $43 \%$ of patients, respectively. Kaplan-Meier estimates of survival at 12, 36, 60, and 120 months were, respectively ( $\% \pm$ standard error), $82.0 \% \pm 2.7 \%, 75.1 \% \pm 3.3 \%, 73.8 \% \pm 3.5 \%$, and $68.3 \% \pm 4.5 \%$ (see Figure $1, A$ and $B$, for confidence limits). Causes of death are listed in Table E8. At 1, 3, and 5 years, estimated survival rates were, respectively, $73.6 \% \pm 4.6 \% ; 58.2 \% \pm 6.1 \%$, and $58.2 \% \pm 6.1 \%$ for
TABLE 3. Perioperative outcomes

\begin{tabular}{|c|c|c|c|}
\hline Outcome & Stroke & $\begin{array}{c}\text { Spinal cord } \\
\text { ischemia }\end{array}$ & Mortality \\
\hline All patients $(n=223)$ & $10(4.5)$ & $6(2.7)^{*}$ & $26(11.7)$ \\
\hline Emergent $(\mathrm{n}=121)$ & $4(3.3)$ & $1(0.8)$ & $17(14.0)$ \\
\hline Elective $(\mathrm{n}=102)$ & $6(5.9)$ & $5(4.9)$ & $9(8.9)$ \\
\hline Zone $0(\mathrm{n}=17)$ & $3(17.6)$ & $1(5.9)$ & $3(17.6)$ \\
\hline Zone $1(\mathrm{n}=17)$ & $2(11.8)$ & $0(0)$ & $2(11.8)$ \\
\hline Zone $2(\mathrm{n}=59)$ & $3(5.1)$ & $2(3.4)$ & $8(13.6)$ \\
\hline Zone $3(n=81)$ & $2(2.5)$ & $1(1.2)$ & $8(9.9)$ \\
\hline Zone $4(\mathrm{n}=33)$ & $0(0)$ & $1(3.0)$ & $3(9.1)$ \\
\hline Zone $5(\mathrm{n}=16)$ & $0(0)$ & $1(6.2)$ & $2(12.5)$ \\
\hline Aneurysm group $(\mathrm{n}=101)$ & $4(4.0)$ & $4(4.0)^{*}$ & $19(18.8)$ \\
\hline Emergent $(\mathrm{n}=32)$ & $0(0)$ & $1(3.1)$ & $11(34.4)$ \\
\hline Elective $(\mathrm{n}=69)$ & $4(5.8)$ & $3(4.3)$ & $8(11.6)$ \\
\hline Zone $0(\mathrm{n}=10)$ & $0(0)$ & $0(0)$ & $2(20.0)$ \\
\hline Zone $1(\mathrm{n}=10)$ & $1(10.0)$ & $0(0)$ & $2(20.0)$ \\
\hline Zone $2(\mathrm{n}=24)$ & $3(12.5)$ & $2(8.3)$ & $5(20.8)$ \\
\hline Zone $3(n=21)$ & $0(0)$ & $0(0)$ & $6(28.6)$ \\
\hline Zone $4(\mathrm{n}=26)$ & $0(0)$ & $1(3.8)$ & $3(11.5)$ \\
\hline Zone $5(\mathrm{n}=10)$ & $0(0)$ & $1(10)$ & $1(10)$ \\
\hline Dissection group $(\mathrm{n}=51)$ & $5(9.8)$ & $2(3.9)^{*}$ & $5(9.8)$ \\
\hline Acute dissection $(\mathrm{n}=26)$ & $3(11.5)$ & $0(0)$ & $4(15.4)$ \\
\hline Chronic dissection $(\mathrm{n}=25)$ & $2(8.0)$ & $2(8.0)$ & $1(4.0)$ \\
\hline Zone $0(\mathrm{n}=6)$ & $3(50.0)$ & $1(16.7)$ & $1(16.7)$ \\
\hline Zone $1(\mathrm{n}=3)$ & $0(0)$ & $0(0)$ & $0(0)$ \\
\hline Zone $2(\mathrm{n}=17)$ & $0(0)$ & $0(0)$ & $2(11.8)$ \\
\hline Zone $3(\mathrm{n}=18)$ & $2(11.1)$ & $1(5.6)$ & $1(5.6)$ \\
\hline Zone $4(\mathrm{n}=4)$ & $0(0)$ & $0(0)$ & $0(0)$ \\
\hline Zone $5(\mathrm{n}=3)$ & $0(0)$ & $0(0)$ & $1(33.3)$ \\
\hline Traumatic group $(\mathrm{n}=59)$ & $1(1.7)$ & $0(0)$ & $1(1.7)$ \\
\hline Emergent $(\mathrm{n}=50)$ & $1(2.0)$ & $0(0)$ & $1(2.0)$ \\
\hline Elective $(\mathrm{n}=9)$ & $0(0)$ & $0(0)$ & $0(0)$ \\
\hline Zone $0(\mathrm{n}=0)$ & - & - & - \\
\hline Zone $1(\mathrm{n}=1)$ & $1(100)$ & $0(0)$ & $0(0)$ \\
\hline Zone $2(\mathrm{n}=15)$ & $0(0)$ & $0(0)$ & $0(0)$ \\
\hline Zone $3(n=41)$ & $0(0)$ & $0(0)$ & $1(4.9)$ \\
\hline Zone $4(\mathrm{n}=0)$ & - & - & - \\
\hline Zone $5(\mathrm{n}=2)$ & $0(0)$ & $0(0)$ & $0(0)$ \\
\hline Septic group $(\mathrm{n}=12)$ & $0(0)$ & $0(0)$ & $1(8.3)$ \\
\hline Emergent $(\mathrm{n}=12)$ & $0(0)$ & $0(0)$ & $1(8.3)$ \\
\hline Elective $(\mathrm{n}=0)$ & - & - & - \\
\hline Zone $0(\mathrm{n}=1)$ & $0(0)$ & $0(0)$ & $0(0)$ \\
\hline Zone $1(\mathrm{n}=3)$ & $0(0)$ & $0(0)$ & $0(0)$ \\
\hline Zone $2(\mathrm{n}=3)$ & $0(0)$ & $0(0)$ & $1(33.3)$ \\
\hline Zone $3(n=1)$ & $0(0)$ & $0(0)$ & $0(0)$ \\
\hline Zone $4(n=3)$ & $0(0)$ & $0(0)$ & $0(0)$ \\
\hline Zone $5(\mathrm{n}=1)$ & $0(0)$ & $0(0)$ & $0(0)$ \\
\hline
\end{tabular}

Values are presented as $\mathrm{n}(\%)$. ${ }^{*}$ Spinal cord ischemia referred to permanent paraplegia (which was observed in 4 out of 6 patients: 3 aneurysms and 1 dissection) and transient paraplegia (observed in 1 aneurysm group patient and 1 dissection group patient).

the aneurysm group, $85.8 \% \pm 5.0 \%, 81.3 \% \pm 6.5 \%$, and $73.9 \% \pm 9.2 \%$ for the dissection group. No late death was observed in the traumatic group and long-term mortality remains at $1.7 \%$. The septic group was too small to draw any firm conclusion. Kaplan-Meier estimates curves of 


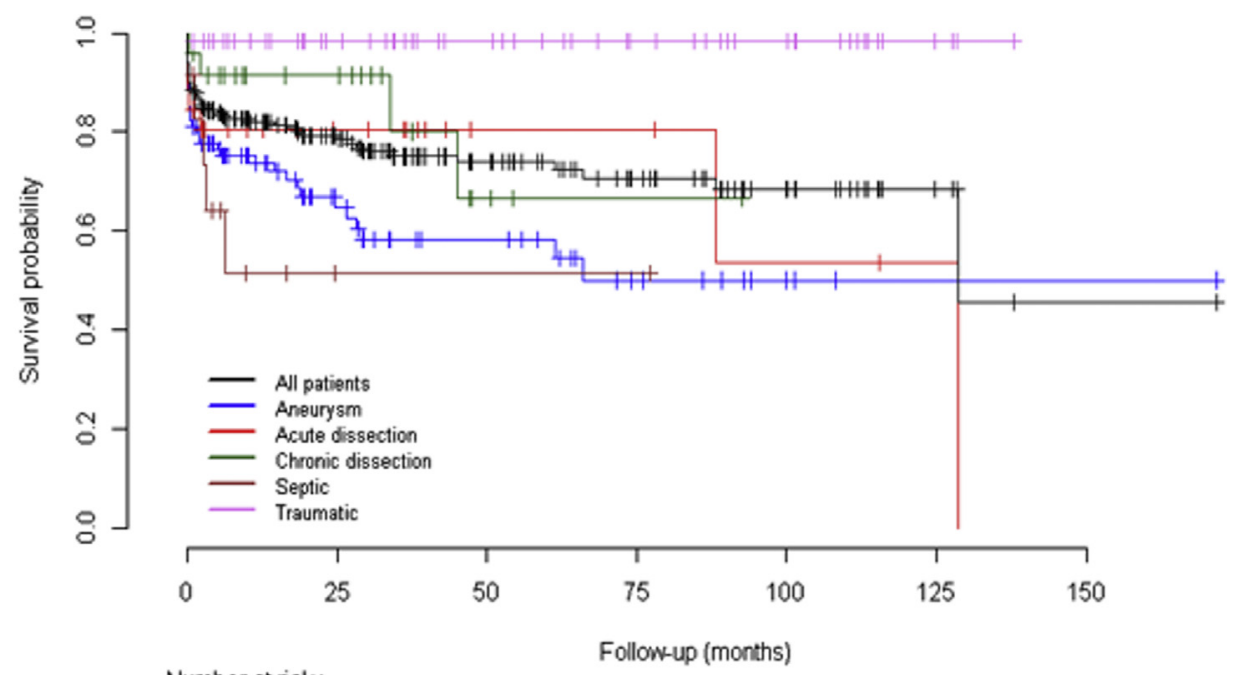

\begin{tabular}{cccccccc}
\multicolumn{2}{c}{ Number at risk: } \\
All patients & 223 & 99 & 58 & 37 & 21 & 6 & 1 \\
Aneurysm & 101 & 31 & 19 & 9 & 3 & 1 & 1 \\
AD & 26 & 12 & 4 & 2 & 1 & 0 & 0 \\
CD & 25 & 13 & 3 & 1 & 0 & 0 & 0 \\
& 12 & 1 & 1 & 1 & 0 & 0 & 0 \\
A Septic & 12 & 42 & 31 & 22 & 16 & 4 & 0
\end{tabular}

FIGURE 1. A, Product-limit survival estimates curves. B, Confidence limits of product-limit survival estimates curves. $A D$, Acute dissection; $C D$, chronic dissection.

survival are drawn in Figure 1. Estimated log-rank test showed statistically significant difference $(P<.0001)$ between estimated survivals.

During follow-up, multivariate analysis did not disclose any predisposing factor of endoleak after TEVAR. There was a trend toward a lower endoleak rate in patients who underwent TEVAR in zone $5(P=.07)$. Endoleak follow-up is reported in Table 4. Furthermore, occurrence of endoleak did not have any significant influence on survival $(P=.58)$ (Figure E3, $A$ and $B)$.

During follow-up, $12.2 \%$ of the patients required reintervention (Tables 5 and 6). Multivariate analysis showed that patients treated for a chronic aortic dissection had a significant higher risk of late reintervention $(P=.001)$ (Table 2). Kaplan-Meier estimates curves of survival-free from aortic complications (reinterventions and endoleaks) at 12, 36, 60, and 120 months were, respectively, $73 \% \pm 3 \%, 64 \% \pm 4 \%$, $62 \% \pm 4 \%$, and $57 \% \pm 5 \%$ (Figure $\mathrm{E} 4, A$ and $B$ ).

\section{DISCUSSION}

In our experience, reported postoperative causes of death show that TEVAR remains a major procedure. Nevertheless, only 3 patients $(1.3 \%)$ had a procedure-related death ( 2 neurologic and 1 retrograde aortic dissection [RAD]). One could argue that other postoperative cause of deaths (MSOF or cardiac, respiratory, or bowel ischemia) are mostly related to preexisting comorbidities that predisposed patients to organ failure. Mortality is clearly influenced by patient selection, with $84 \%$ of patients presenting
American Society of Anesthesiologists (ASA) score $\geq 3$ and $54 \%$ of emergent procedures.

This study demonstrated that outcomes after TEVAR were pathology specific. Statistical analysis found that early mortality rate for patients with aneursyms $(18.8 \%)$ was higher than patients with traumatic aortic transection $(1.7 \%)(P<.01)$. Comparison with the dissection group or septic group could not demonstrate any significant difference between the groups, but the aneurysm group early mortality seems to be higher than other groups' mortality (respectively, 9.8\% and 8.3\%). This difference is particularly obvious for traumatic ruptures. Clearly, with only $1 \mathrm{pa}-$ tient treated in both zone 0 and 1 , procedures for traumatic aortic disruption are much less invasive than procedures for the aneurysm, dissection, or septic groups because aortic arch debranching for zones 0 and 1 were performed in $19.8 \%, 17.6 \%$, and $33.3 \%$, respectively. Nevertheless, log-rank tests show a significant higher survival for this group made up of patients with multiple acute comorbidities. For this specific pathology, TEVAR has changed short- and long-term prognosis, avoiding cardiopulmonary bypass for patients with cerebral or abdominal trauma. Perioperative mortality in the aneurysm group $(18.8 \%)$ seems to be higher than previously reported mortality rates. ${ }^{9-17}$ Composition of our aneurysm group may partially explain our results. With $83 \%$ of patients having an ASA score $\geq 3$, including $24 \%$ of aortic rupture, our group has an important operative risk. ${ }^{21}$ For example, 11 of 32 emergent patients died, representing $57.9 \%$ of the aneurysm 

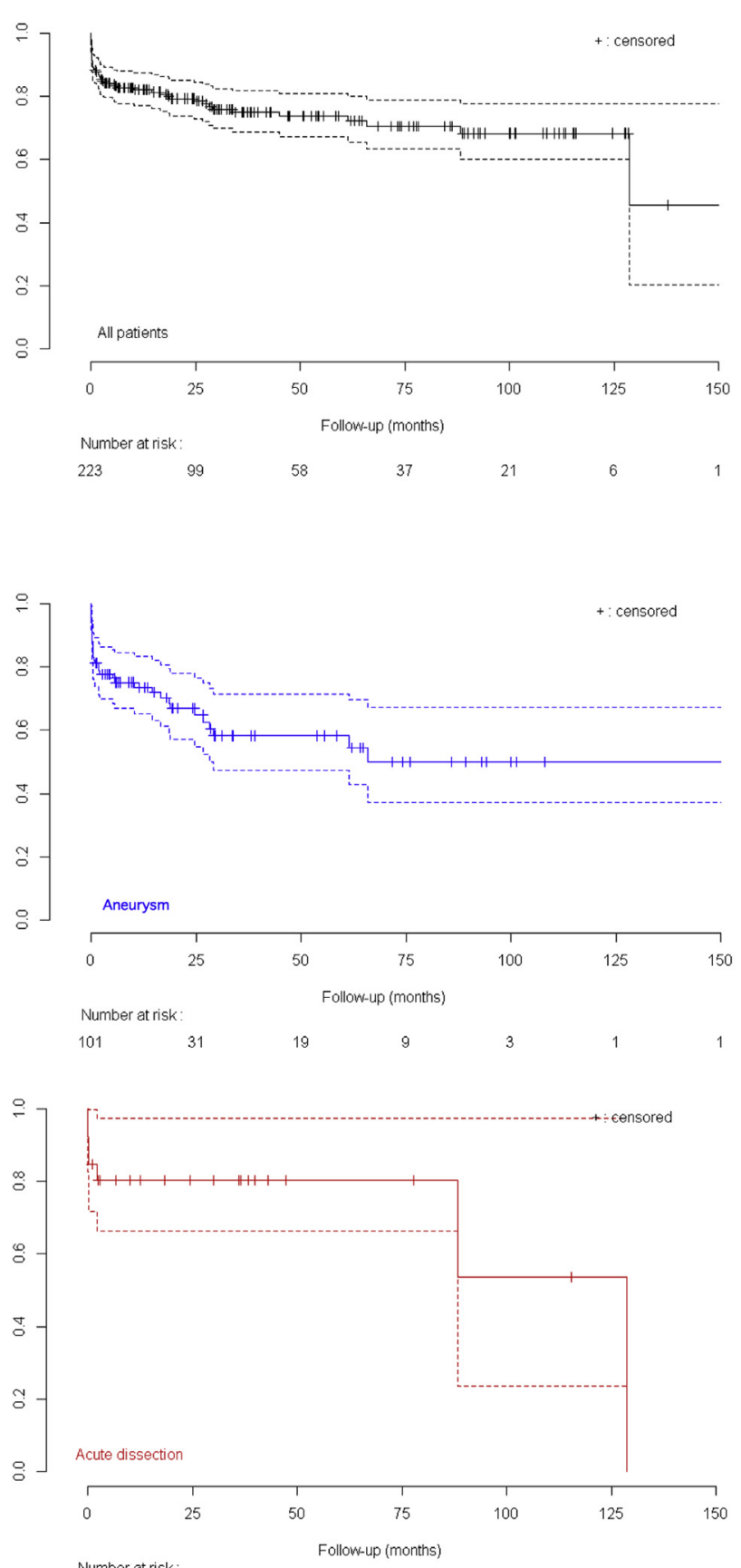

B $26 \quad 12$

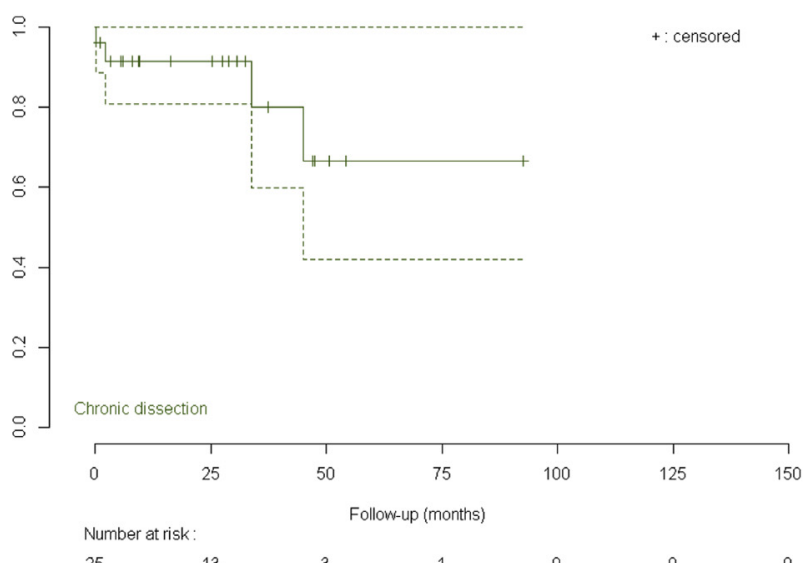

$25-13=3$
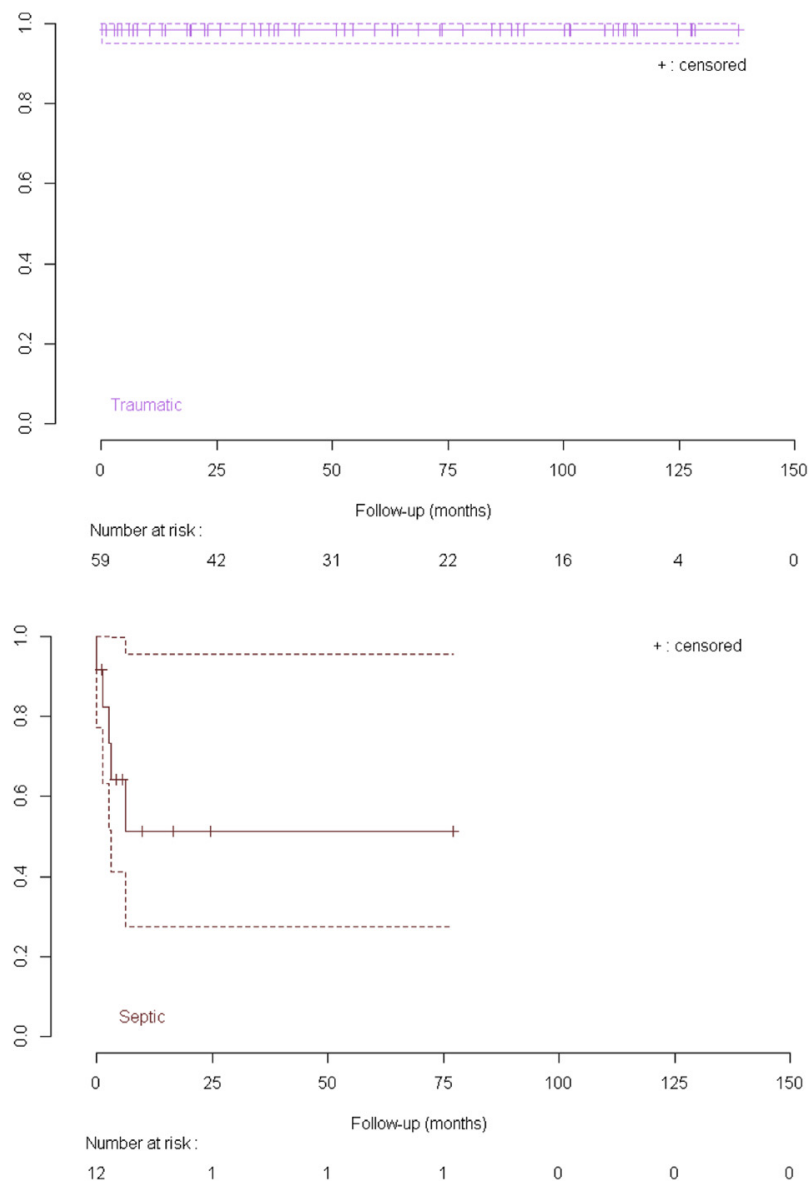

FIGURE 1. (continued).

mortality. In comparison, Leurs and colleagues ${ }^{13}$ reported a $10.4 \%$ mortality rate for $58 \%$ of patients with an ASA score $\geq 3$.

Even in cases where there was no statistical difference, perioperative mortality rate for all patients seems to be also higher for aortic arch disease treated with debranching techniques $(11.8 \%-17.6 \%)$ than for patients treated in zone 3 or $4(9.1 \%$ and $9.9 \%)$. This difference had been expected as the difference during traditional repair. The main reason is the anatomic challenge represented by SAV: During debranching or stent-graft deployment procedures, many issues may appear such as stroke, upper limb ischemia, or RAD. ${ }^{22}$ Statistical analysis could not demonstrate any significant difference between different zone mortality, but it is probably due to the small number of patients. Complexity of procedures involving aortic arch is also demonstrated by 
TABLE 4. Endoleak follow-up

\begin{tabular}{|c|c|c|c|c|c|}
\hline & $\begin{array}{c}\text { All patients } \\
(\mathbf{n}=197) \\
\end{array}$ & $\begin{array}{l}\text { Aneurysm group } \\
\quad(n=82)\end{array}$ & $\begin{array}{c}\text { Dissection group } \\
\quad(n=46)\end{array}$ & $\begin{array}{c}\text { Traumatic group } \\
\quad(\mathbf{n}=\mathbf{5 8})\end{array}$ & $\begin{array}{c}\text { Septic group } \\
(\mathrm{n}=11)\end{array}$ \\
\hline Patients presenting with any type of endoleak & $36(18.3)^{*}$ & $20(25.6)^{*}$ & $14(30.4)$ & $0(0)$ & $2(18.2)$ \\
\hline Type I & $21(10.7)$ & $9(11.0)$ & $10(21.7)$ & $0(0)$ & $2(18.2)$ \\
\hline Type Ia & $15(7.6)$ & $6(7.3)$ & $7(15.2)$ & $0(0)$ & $2(18.2)$ \\
\hline Type Ib & $6(3.0)$ & $3(3.7)$ & $3(6.5)$ & $0(0)$ & $0(0)$ \\
\hline Type II & $11(5.6)$ & $7(8.5)$ & $4(8.7)$ & $0(0)$ & $0(0)$ \\
\hline Type III & $3(1.5)$ & $3(3.7)$ & $0(0)$ & $0(0)$ & $0(0)$ \\
\hline Type V (endotension) & $4(2.0)$ & $4(4.9)$ & $0(0)$ & $0(0)$ & $0(0)$ \\
\hline
\end{tabular}

*Three patients presented 2 types of endoleak: 1 patient presented with 2 type-III endoleaks, 1 patient presented with a type Ib endoleak and an indeterminate endoleak, and 1 patient presented with a type II and a type Ia endoleak.

a higher migration rate in patients who underwent TEVAR in zone 0,1 , or 2 , although it fell short of statistical significance $(P=.06)$. However, statistical analysis showed that the C-Tag device was statistically associated with a higher migration rate $(P=.02)$. The $\mathrm{C}$-Tag release system, without bare-metal stent and proximal hooks, is probably an explanation of migration risk during TEVAR.

Neurologic morbidity in our study is quite similar to previously reported outcomes. SCI occurred during the perioperative period for $2.7 \%$ of patients. Literature showed similar results for $2.0 \%$ to $9.3 \%$ of the patients. Strokes occurred in $4.5 \%$ of patients. The literature shows similar results for $3 \%$ to $4.8 \%$ of patients. ${ }^{9-17}$ Study of our cohort found that acute aortic dissection was significantly associated with a higher proportion of strokes $(P=.02)$. It is probably because major fragility of the aortic wall in this indication can facilitate the extension of the dissection to SAV during wire manipulations, vessel clamping, or endograft deployment.

RAD is a serious complication after TEVAR. It has been reported in $1 \%$ to $2 \%$ of cases. ${ }^{22-24}$ It is likely that RAD is more frequent after hybrid arch procedures ${ }^{22-24}$ compared with single TEVAR. This was confirmed by multivariate analysis, which showed the significant predictor of RAD was TEVAR procedure performed in zone 0 or $1(P<.001)$. During our TEVAR experience, we reported a total of 8 RADs $(3.6 \%)$.
This rate is only $2.7 \%$ during perioperative period. Patterson and colleagues ${ }^{25}$ also reported recently a RAD risk during long-term follow-up with an increase incidence from $3.2 \%$ to $4.9 \%$ for acute type B aortic dissection and from $1.5 \%$ to $2.3 \%$ for chronic dissections. We recently modified our approach in zone 0 to avoid RAD: We used rapid pacing not only during stent-graft deployment but also during aortic crossclamping and declamping.

Logically, statistical analysis found that zones 0 and 1 were associated with a higher rate $(P<.001)$ of early reintervention. Complexity of these procedures, including SAV debranching, is an additional source of adverse events (eg, RAD, bypass stenosis, or thrombosis) that could lead to reintervention. Long-term follow-up shows that a main reason of failure after TEVAR is the occurrence of major endoleak. The percentage of type I or III endoleak reported is very variable in publications. ${ }^{9-17}$ Desai and colleagues ${ }^{9}$ reported a major endoleak rate of $12.7 \%$, including $67 \%$ requiring reintervention. However, in our series, the major endoleak rate was $10.3 \%$ (24 for 23 patients) and only $7.6 \%$ (15 patients) required a reintervention to treat the endoleak. Reintervention was not necessary in $56.4 \%$ of endoleaks ( $28.2 \%$ of spontaneous thrombosis and $28.2 \%$ are still being followed).

In the present study, the endoleak rate was higher in the dissection group $(30.4 \%)$ than in the aneurysm group

TABLE 5. Reported indications for late reintervention

\begin{tabular}{|c|c|c|c|c|c|}
\hline Indication for reintervention & $\begin{array}{c}\text { All patients } \\
(\mathbf{n}=197)\end{array}$ & $\begin{array}{l}\text { Aneurysm group } \\
\quad(n=82)\end{array}$ & $\begin{array}{l}\text { Dissection group } \\
\quad(n=46)\end{array}$ & $\begin{array}{l}\text { Traumatic group } \\
\quad(\mathbf{n}=\mathbf{5 8})\end{array}$ & $\begin{array}{l}\text { Septic group } \\
\quad(\mathbf{n}=11)\end{array}$ \\
\hline Total patients & $24(12.2)$ & $9(11.0)^{*}$ & $10(21.7) \dagger$ & $4(6.9)$ & $1(9.1)$ \\
\hline Aneurysmal expansion of aorta & $1(0.5)$ & $0(0)$ & $1(2.2)$ & $0(0)$ & $0(0)$ \\
\hline Continued perfusion of distal false lumen & $5(2.5)$ & $0(0)$ & $5(10.9)$ & $0(0)$ & $0(0)$ \\
\hline Endograft collapse & $1(0.5)$ & $0(0)$ & $0(0)$ & $1(1.7)$ & $0(0)$ \\
\hline Type Ia endoleak & $8(4.1)$ & $3(3.7)$ & $5(10.9)$ & $0(0)$ & $0(0)$ \\
\hline Type Ib endoleak & $2(1.0)$ & $2(3.8)$ & $0(0)$ & $0(0)$ & $0(0)$ \\
\hline Type III endoleak & $1(0.5)$ & $1(1.2)$ & $0(0)$ & $0(0)$ & $0(0)$ \\
\hline Other endoleak & $2(1.0)$ & $2(3.8)$ & $0(0)$ & $0(0)$ & $0(0)$ \\
\hline Endograft infection & $3(1.5)$ & $1(1.2)$ & $1(2.2)$ & $0(0)$ & $1(9.1)$ \\
\hline Peripheral & $4(2.0)$ & $1(1.2)$ & $0(0)$ & $3(5.2)$ & $0(0)$ \\
\hline
\end{tabular}

Values are presented as n (\%). * One patient with a type Ib endoleak initially treated by additional stent-graft presented an indeterminate additional endoleak treated by open surgery. $\uparrow$ Two patients underwent reoperation twice: One patient treated by open surgery for an abdominal aneurysm evolution of chronic dissection presented a type 1 a endoleak treated by additional stent-graft. Another patient with an aneurysmal expansion of distal aorta due to false lumen perfusion had 2 additional procedures: 1 distal stent-graft deployment and 1 bronchial resection for an aortobronchial fistulae during follow-up. 
TABLE 6. Late types of reintervention

\begin{tabular}{|c|c|c|c|c|c|}
\hline Mode of reintervention & $\begin{array}{c}\text { All patients } \\
(\mathrm{n}=197)\end{array}$ & $\begin{array}{c}\text { Aneurysm } \\
\text { group }(\mathbf{n}=\mathbf{8 2})\end{array}$ & $\begin{array}{c}\text { Dissection } \\
\text { group }(n=46)\end{array}$ & $\begin{array}{c}\text { Traumatic } \\
\operatorname{group}(\mathbf{n}=\mathbf{5 8})\end{array}$ & $\begin{array}{c}\text { Septic } \\
\text { group }(n=11)\end{array}$ \\
\hline Total patients & $24(12.2)$ & $9(11.0)^{*}$ & $10(21.7) \dagger$ & $4(6.9)$ & $1(9.1)$ \\
\hline Proximal/distal extension of stent-graft/additional stent-graft & $14(7.1)$ & $5(6.1)$ & $9(19.6)$ & $0(0)$ & $0(0)$ \\
\hline Supra-aortic bypass & $6(3.0)$ & $1(1.2) \ddagger$ & $3(6.5) \ddagger$ & $2(3.4)$ & $0(0)$ \\
\hline Open thoracic aortic surgery & $6(3.0)$ & $4(4.9)$ & $0(0)$ & $1(1.7)$ & $1(9.1)$ \\
\hline Open abdominal aortic surgery & $2(1.0)$ & $0(0)$ & $2(4.3)$ & $0(0)$ & $0(0)$ \\
\hline Peripheral stent & $2(1.0)$ & $1(1.2)$ & $0(0)$ & $1(1.7)$ & $0(0)$ \\
\hline
\end{tabular}

Values are presented as $\mathrm{n}(\%)$. * One patient with a type Ib endoleak initially treated by additional stent-graft presented an indeterminate additional endoleak treated by open surgery. $\dagger$ Two patients underwent reoperation twice: One patient treated by open surgery for an abdominal aneurysm evolution of chronic dissection presented a type 1a endoleak treated by additional stent-graft. Another patient with an aneurysmal expansion of distal aorta due to false lumen perfusion had 2 additional procedures: 1 distal stent-graft deployment and 1 bronchial resection for an aortobronchial fistulae during follow-up. †Debranching procedure for additional stent-graft.

$(25.6 \%)$ or the septic group $(18.2 \%)$, without statistical significance. In the traumatic group, during follow-up, no endoleak was observed. We did not observed device issues. Causes of reintervention were related to degeneration of the landing zones over time. This is corroborated by the not-uncommon risk of distal or proximal aortic reintervention after open repair for degenerative aneurysm or chronic dissection, whereas aortic reintervention after open repair is clearly uncommon after traumatic transection or acute type $\mathrm{B}$ dissection. One explanation is that aneurysm or dissection pathologies are chronic and involved a long aortic segment; it is sometimes necessary to pile up stent-grafts. On the other hand, traumatic lesions appear most of the time on healthy aortas and concern a very isolated portion. But the traumatic group had specific complications related to these healthy aortas: Small aortic diameter and aortic arch major angulation may induce endograft collapse. ${ }^{26-28}$

Type I endoleak appears to be more frequent in chronic dissection ( 9 out of 25 patients; 36\%) than in acute dissection ( 1 out of 26 patients; $4 \%)(P<.05)$. The explanation is that many acute dissections (19 out of $26 ; 73 \%$ ) were not treated for aneurysmal expansion (but rather, rupture or malperfusion). For these patients, type I endoleak is exceptional: Aortic diameter remains stable and provides a long neck for endograft fixation. Furthermore, without aortic enlargement, the aortic wall remains superimposed on the stent-graft, without possibility for blood flow to perfuse the aneurysm.

For aneurysms, surprisingly, endoleaks appear to be more frequent in the elective group (15 out of 69 patients; $22 \%$ ) than emergent aneurysms (5 out of 32 patients; $16 \%$ ). Nevertheless, this discrepancy was not statistically significant $(P=.47)$. Multivariate analysis could not demonstrate any significant risk factors in subpopulations.

Reintervention has been an ongoing issue with TEVAR. In the present study, secondary procedure rate was $13.2 \%$ during follow-up, but this rate was statistically different between groups. The dissection group presented a reintervention rate of $23.9 \%$, which was higher than other groups. Analysis found that chronic aortic dissection was associated with a higher risk of late reintervention $(P=.01)$.
Several limitations of this study should be considered. Results must be interpreted within the context of it being a retrospective study design without a control group to compare against. A direct consequence is the impossibility to conclude any superiority or noninferiority between our cohort of patients treated by stent-graft and patients treated by conventional surgery. Furthermore, the single-institution nature of this study limited the cohort sample size to 223 patients. Unfortunately, the great diversity of pathologies, modalities of care, and landing zones revealed an important heterogeneity of our cohort, which is composed of relatively small groups. This limitation leads to underpowering of the study and outcome results, leading to the possibility of mistakes during analysis.

\section{CONCLUSIONS}

Long-term outcomes show an important heterogeneity of reported results with specific long-term complications. TEVAR performed for aortic traumatic rupture has totally changed the prognosis of these patients. Results for patients treated for a thoracic aortic aneurysm are acceptable despite important perioperative mortality, probably due to our rate of emergent procedures. Aortic dissection remains a challenging pathology that should be considered as a chronic pathology with an important reintervention rate. Septic aortic diseases remain extremely rare, with an important mortality rate and the place of TEVAR is still under evaluation. ${ }^{29,30}$ We now consider TEVAR the first choice in the treatment of descending thoracic aorta aneurysms, aortic disruptions, and thoracic aortic dissections.

Conventional surgical repair of aortic arch remains substantial and we also consider hybrid TEVAR as the first choice in high-risk patients or after previous aortic surgery despite early and late specific adverse events.

Improvement of endovascular devices may increase flexibility and conformability of stent-grafts to decrease morbidity and mortality rates. ${ }^{31}$ Better patient selection through multidisciplinary discussions may also improve TEVAR outcomes, selecting patients for open repair, endovascular repair, or hybrid techniques (such as debranching or frozen elephant trunk). Frozen elephant trunk has the 
potential to further minimize morbidity by avoiding the second-step procedure of conventional surgical repair and the theoretical advantage over hybrid repair of preventing the occurrence of type Ia endoleak and RAD. The present optimized selection criteria for use of frozen elephant trunk in elective cases has been associated with a remarkable decrease in mortality compared with initial experiences. ${ }^{32}$ Total endovascular repair of the aortic arch remains an experimental technique but should be assessed in the future. Several comparative studies are mandatory to determine indications of each technique.

\section{Conflict of Interest Statement}

Authors have nothing to disclose with regard to commercial support.

\section{References}

1. Dake MD, Miller DC, Semba CP, Mitchell RS, Walker PJ, Liddell RP. Transluminal placement of endovascular stent-grafts for the treatment of descending thoracic aortic aneurysms. N Engl J Med. 1994;331:1729-34.

2. Svensson LG, Kouchoukos NT, Miller DC, Bavaria JE, Coselli JS, Curi MA, et al. Expert consensus document on the treatment of descending thoracic aortic disease using endovascular stent-grafts. Ann Thorac Surg. 2008;85(Suppl): S1-41.

3. Erbel R, Alfonso F, Boileau C, Dirsch O, Eber B, Haverich A, et al. Diagnosis and management of aortic dissection. Eur Heart J. 2001:22:1642-81.

4. Greenhalgh RM, Brown LC, Powell JT, Thompson SG, Epstein D, Sculpher MJ, et al. Endovascular versus open repair of abdominal aortic aneurysm. $N$ Engl J Med. 2010;362:1863-71.

5. Bergeron P, Mangialardi N, Costa P, Coulon P, Douillez V, Serreo E, et al. Great vessel management for endovascular exclusion of aortic arch aneurysms and dissections. Eur J Vasc Endovasc Surg. 2006:32:38-45.

6. Czerny M, Funovics M, Schoder M, Loewe C, Lammer J, Grabenwöger M, et al. Transposition of the supra-aortic vessels before stent-grafting the aortic arch and descending aorta. J Thorac Cardiovasc Surg. 2013;145(Suppl):S91-7.

7. Canaud L, Hireche K, Berthet J-P, Branchereau P, Marty-Ané C, Alric P. Endovascular repair of aortic arch lesions in high-risk patients or after previous aortic surgery: midterm results. J Thorac Cardiovasc Surg. 2010;140:52-8.

8. Canaud L, Joyeux F, Ziza V, Branchereau P, Marty-Ané C, Alric P. Hemi-aortic arch debranching for hybrid aortic arch repair by sequential transposition of the left common carotid and subclavian arteries. J Thorac Cardiovasc Surg. 2013; 145:764-7.

9. Desai ND, Pochettino A, Szeto WY, Moser GW, Moeller PJ, Sodhi N, et al. Thoracic endovascular aortic repair: evolution of therapy, patterns of use, and results in a 10-year experience. J Thorac Cardiovasc Surg. 2011;142:587-94.

10. Chaikof EL, Mutrie C, Kasirajan K, Milner R, Chen EP, Veeraswamy RK, et al. Endovascular repair for diverse pathologies of the thoracic aorta: an initial decade of experience. J Am Coll Surg. 2009;208:802-16.

11. Fairman RM, Tuchek JM, Lee WA, Kasirajan K, White R, Mehta M, et al. Pivotal results for the Medtronic Valiant Thoracic Stent-graft System in the VALOR II trial. J Vasc Surg. 2012:56:1222-31.

12. Foley PJ, Criado FJ, Farber MA, Kwolek CJ, Mehta M, White RA, et al. Results with the Talent thoracic stent-graft in the VALOR trial. J Vasc Surg. 2012;56: 1214-21.

13. Leurs LJ, Bell R, Degrieck Y, Thomas S, Hobo R, Lundbom J, et al. Endovascular treatment of thoracic aortic diseases: combined experience from the EUROSTAR and United Kingdom Thoracic Endograft registries. J Vasc Surg. 2004:40:670-9.
14. Matsumura JS, Cambria RP, Dake MD, Moore RD, Svensson LG, Snyder S International controlled clinical trial of thoracic endovascular aneurysm repair with the Zenith TX2 endovascular graft: 1-year results. J Vasc Surg. 2008;47: 247-57.

15. Lee WA, Daniels MJ, Beaver TM, Klodell CT, Raghinaru DE, Hess PJ Jr. Late outcomes of a single-center experience of 400 consecutive thoracic endovascular aortic repairs. Circulation. 2011;123:2938-45.

16. Rodriguez JA, Olsen DM, Shtutman A, Lucas LA, Wheatley G, Alpern J, et al Application of endograft to treat thoracic aortic pathologies: a single center experience. J Vasc Surg. 2007;46:413-20.

17. Riambau V, Zipfel B, Coppi G, Czerny M, Tealdi DG, Ferro C, et al. Final operative and midterm results of the European experience in the RELAY Endovascular Registry for Thoracic Disease (RESTORE) study. J Vasc Surg. 2011;53: 565-73.

18. Fillinger MF, Greenberg RK, McKinsey JF, Chaikof EL. Reporting standards for thoracic endovascular aortic repair (TEVAR). J Vasc Surg. 2010;2:1022-33.

19. Alric P, Canaud L, Branchereau P, Marty-Ané C. Traitement endovasculaire des anévrysmes de l'aorte thoracique descendante. EMC Techniques chirurgicales Chirurgie vasculaire. 2012;7:1-20.

20. Hinchliffe RJ, Thompson MM. ADSORB: a prospective randomised study on the efficacy of endovascular grafting vs. best medical treatment in uncomplicated acute dissection of the descending aorta. Eur J Vasc Endovasc Surg. 2012;44 $38-9$.

21. Jonker FH, Trimarchi S, Verhagen HJ, Moll FL, Sumpio BE, Muhs BE. Metaanalysis of open versus endovascular repair for ruptured descending thoracic aortic aneurysm. J Vasc Surg. 2010;51:1026-32.

22. Antoniou GA, El Sakka K, Hamady M, Wolfe JH. Hybrid treatment of complex aortic arch disease with supra-aortic debranching and endovascular stent-graft repair. Eur J Vasc Endovasc Surg. 2010;39:683-90.

23. Dong ZH, Fu WG, Wang YQ, Guo DQ, Xu X, Ji Y, et al. Retrograde type A aortic dissection after endovascular stent-graft placement for treatment of type B dissection. Circulation. 2009;119:735-41.

24. Eggebrecht H, Thompson M, Rousseau H, Czerny M, Lönn L, Mehta RH, et al European Registry on Endovascular Aortic Repair Complications. Retrograde ascending aortic dissection during or after thoracic aortic stent-graft placement: insight from the European Registry on Endovascular Aortic Repair Complications. Circulation. 2009;120:276-81.

25. Patterson B, Holt P, Nienaber C, Cambria R, Fairman R, Thompson M. Aortic pathology determines midterm outcome after endovascular repair of the thoracic aorta: report from the Medtronic Thoracic Endovascular Registry (MOTHER) database. Circulation. 2013;127:24-32.

26. Canaud L, Alric P, Desgranges P, Marzelle J, Marty-Ané C, Becquemin J-P. Factors favoring stent-graft collapse after thoracic endovascular aortic repair. $J$ Thorac Cardiovasc Surg. 2010;139:1153-7.

27. Idu MM, Reekers JA, Balm R, Ponsen K-J, de Mol BA, Legemate DA. Collapse of a stent-graft following treatment of a traumatic thoracic aortic rupture. $J$ Endovasc Ther. 2005;12:503-7.

28. Mestres G, Maeso J, Fernandez V, Matas M. Symptomatic collapse of a thoracic aorta endoprosthesis. J Vasc Surg. 2006;43:1270-3

29. Canaud L, Ozdemir BA, Bahia S, Hinchliffe R, Loftus I, Thompson M. Thoracic endovascular aortic repair for aortobronchial fistula. Ann Thorac Surg. 2013;96: 1117-21.

30. Chiesa R, Melissano G, Marone EM, Kahlberg A, Marrocco-Trischitta MM, Tshomba Y. Endovascular treatment of aortoesophageal and aortobronchial fistulae. J Vasc Surg. 2010;51:1195-202.

31. Canaud L, Cathala P, Joyeux F, Branchereau P, Marty-Ané C, Alric P. Improvement in conformability of the latest generation of thoracic stent-grafts. J Vasc Surg. 2013;57:1084-9.

32. Jakob H, Tsagakis T. International E-vita open registry. Ann Cardiothorac Surg 2013;2:296-9.

Key Words: TEVAR, endovascular, aorta, stent-graft, aortic arch 


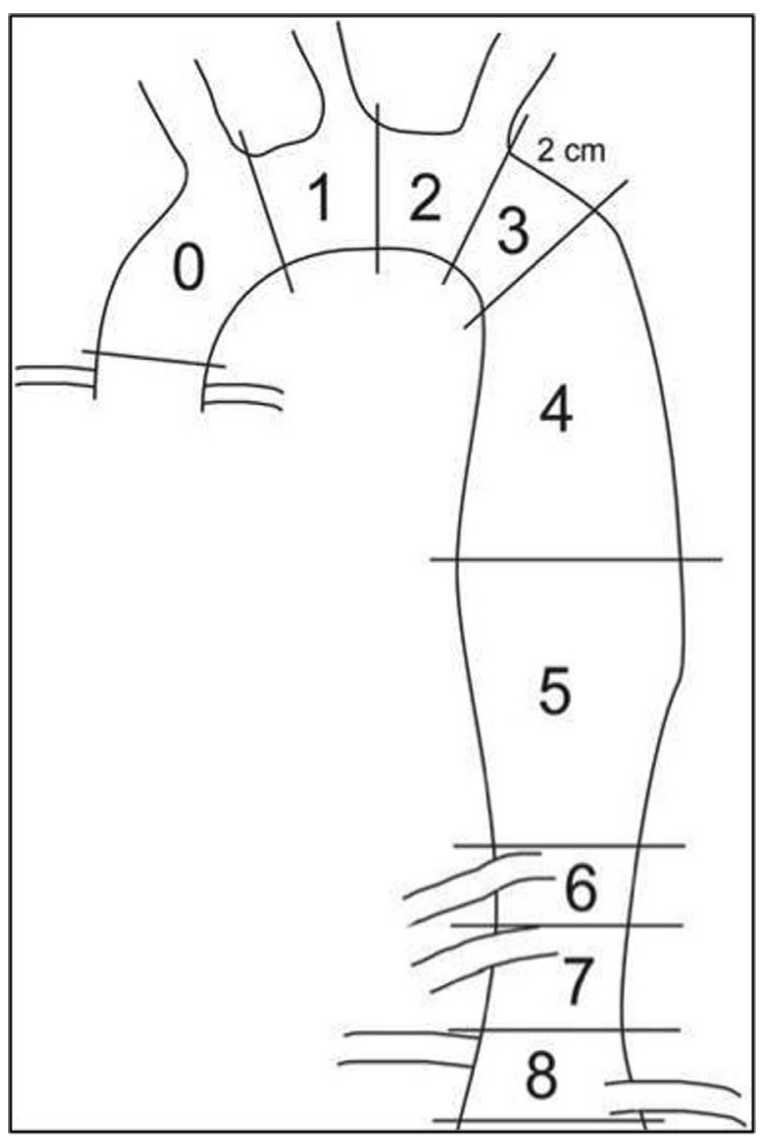

FIGURE E1. Landing zones described by Fillinger and the Society for Vascular Surgery. ${ }^{18}$

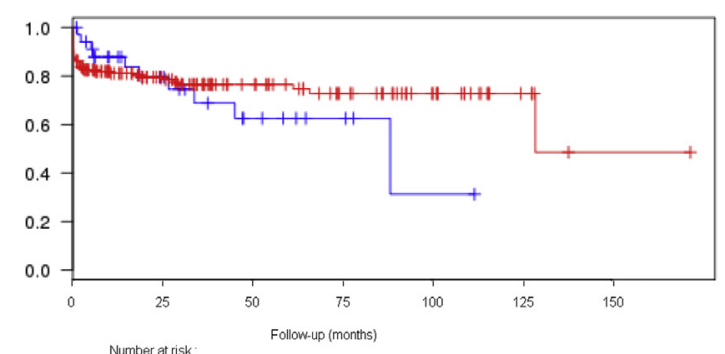

$\begin{array}{llllllll}\text { A With endoleak } & 35 & 20 & 11 & 11 & 2 & & \\ \text { Without endoleak } & 188 & 83 & 76 & 39 & 39 & 39 & 3\end{array}$

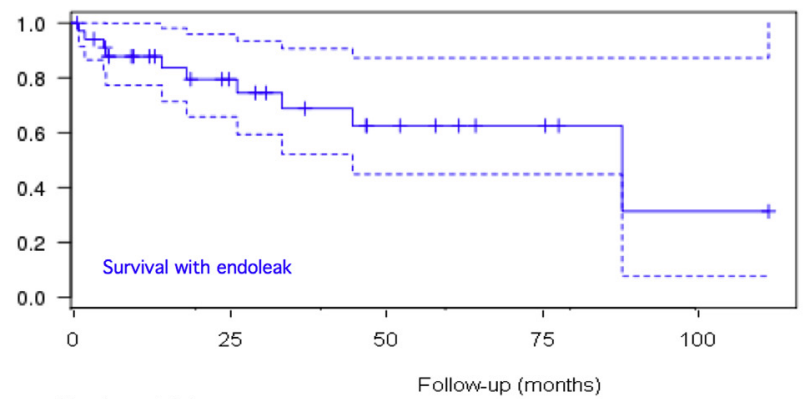

Number at risk:

$35 \quad 20$

11

11

2

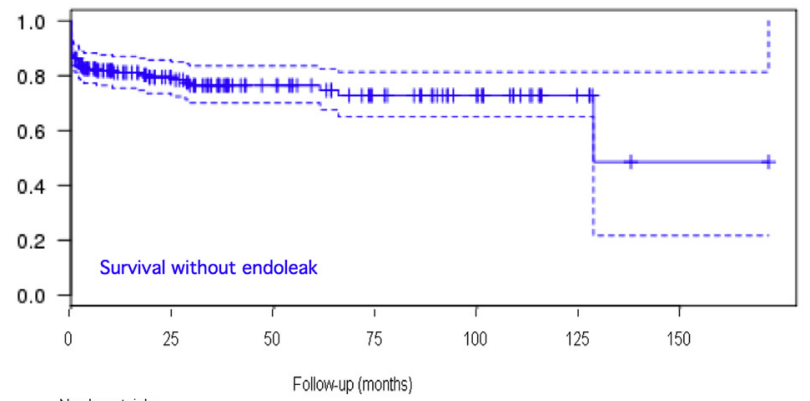

$\begin{array}{llllllll}\text { B } & 188 & 83 & 76 & 39 & 39 & 39 & 39\end{array}$

FIGURE E3. A, Product-limit survival with and without endoleak estimate curves. B, Confidence limits of product-limit survival with and without endoleak estimate curves.

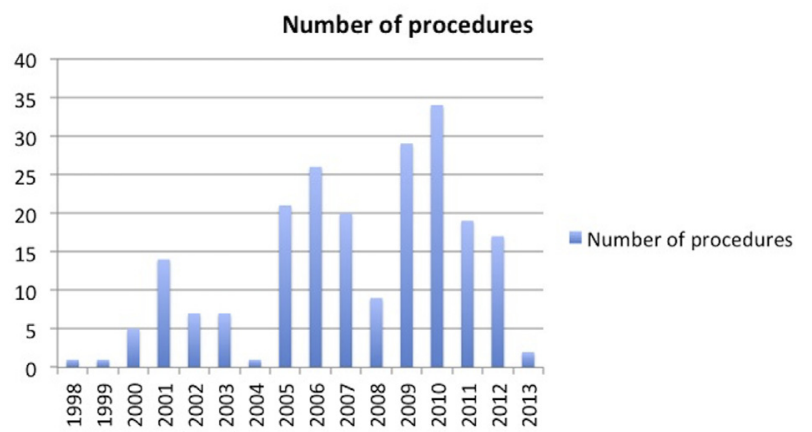

FIGURE E2. Number of procedures by year. 


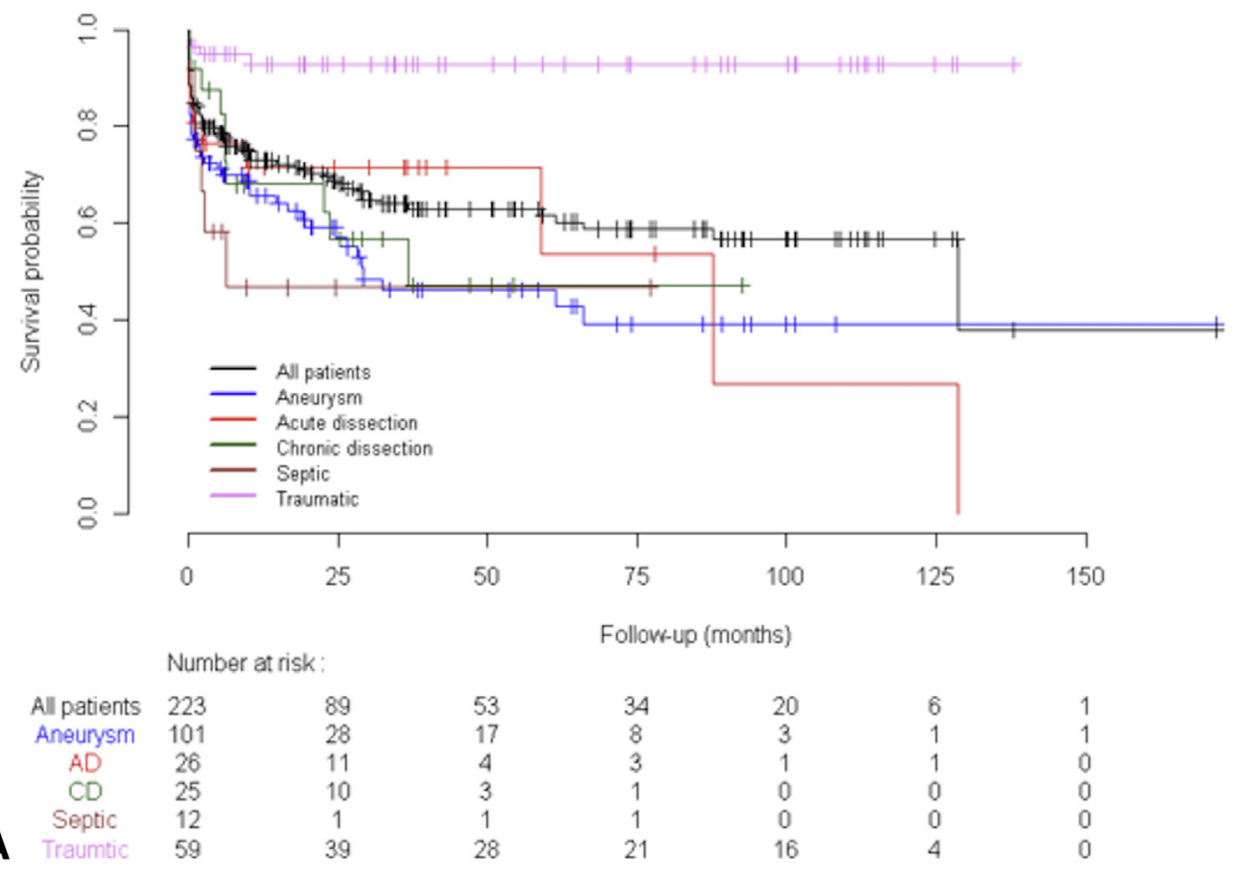

FIGURE E4. A, Product-limit survival free from aortic complications estimate curves. B, Confidence limits of product-limit survival free from aortic complications estimate curves. $A D$, Acute dissection; $C D$, chronic dissection. 

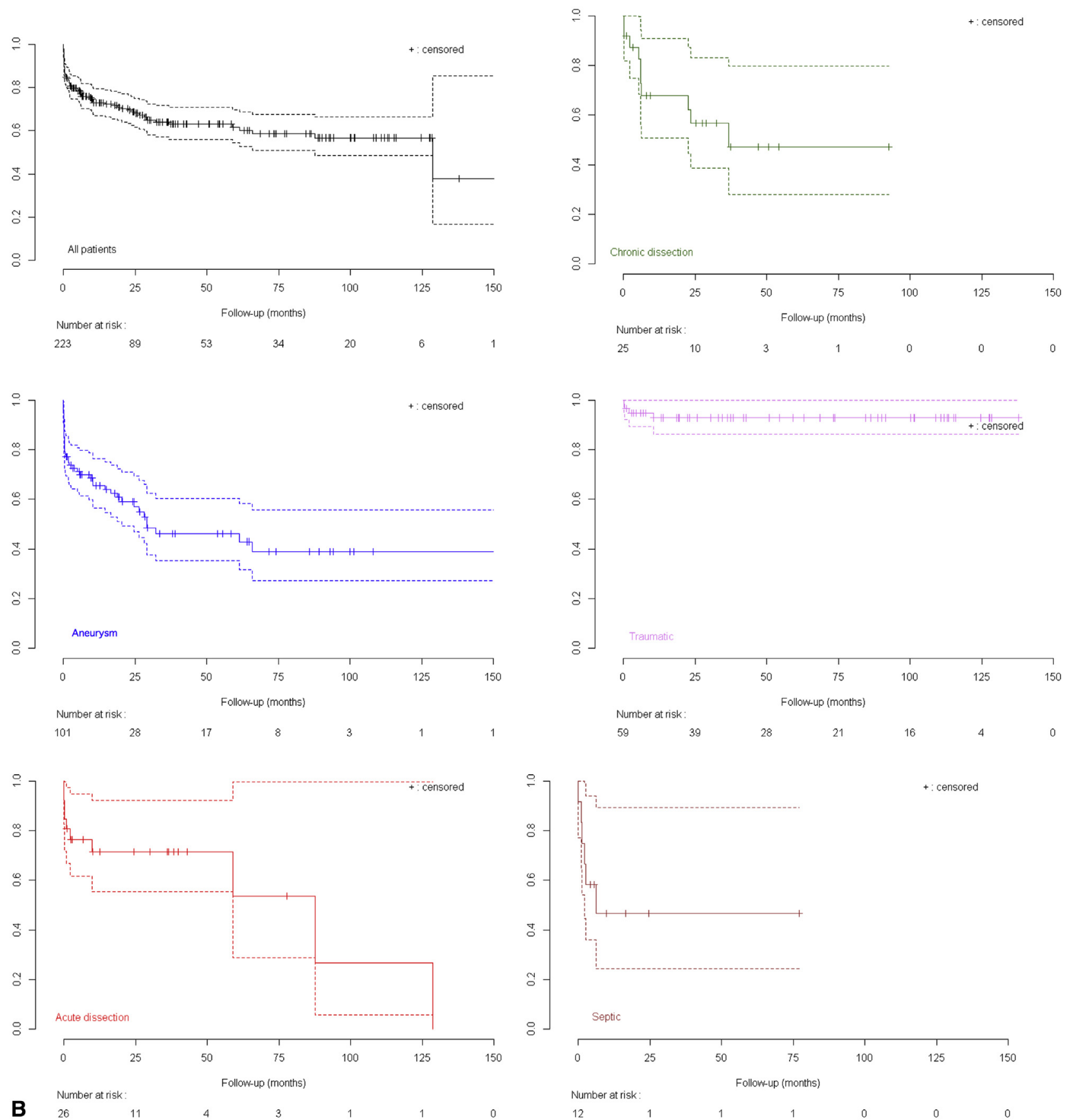

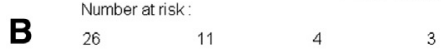

FIGURE E4. (continued). 
TABLE E1. Stent-grafts used

\begin{tabular}{|c|c|c|c|c|c|}
\hline Endograft & Total & Aneurysm group & Dissection group & Traumatic group & Septic group \\
\hline \multirow[t]{2}{*}{ Total } & $280(100)$ & $139(50)$ & $68(24)$ & $61(22)$ & $12(4)$ \\
\hline & {$[32,23,67,98,40,20]$} & {$[18,13,30,33,32,13]$} & {$[13,6,19,21,5,4]$} & {$[0,1,15,43,0,2]$} & {$[1,3,3,1,3,1]$} \\
\hline \multirow[t]{2}{*}{$\mathrm{TAG}^{*}$} & $127(45)$ & $73(26)$ & $27(10)$ & $22(8)$ & $5(2)$ \\
\hline & {$[9,7,32,46,21,12]$} & {$[8,5,16,18,18,8]$} & {$[1,2,10,12,1,1]$} & {$[0,0,5,15,0,2]$} & {$[0,0,1,1,2,1]$} \\
\hline \multirow[t]{2}{*}{ Valiant-Captivia $\dagger$} & $45(16)$ & $15(5)$ & $17(6)$ & $10(4)$ & $3(1)$ \\
\hline & {$[9,4,11,17,3,1]$} & {$[3,1,2,6,3,0]$} & {$[6,1,5,4,0,1]$} & {$[0,1,2,7,0,0]$} & {$[0,1,2,0,0,0]$} \\
\hline \multirow[t]{2}{*}{ C-TAG* } & $37(13)$ & $22(8)$ & $10(4)$ & $4(1)$ & $1(0)$ \\
\hline & {$[5,9,7,11,4,1]$} & {$[2,6,4,6,3,1]$} & {$[3,3,3,1,0,0]$} & {$[0,0,0,4,0,0]$} & {$[0,0,0,0,1,0]$} \\
\hline \multirow[t]{2}{*}{ Valiant $\dagger$} & $35(13)$ & $13(5)$ & $8(3)$ & $11(4)$ & $3(1)$ \\
\hline & {$[9,3,10,12,1,0]$} & {$[5,1,5,1,1,0]$} & {$[3,0,1,4,0,0]$} & {$[0,0,4,7,0,0]$} & {$[1,2,0,0,0,0]$} \\
\hline \multirow[t]{2}{*}{ Talent $\dagger$} & $19(7)$ & $5(2)$ & $2(1)$ & $12(4)$ & $0(0)$ \\
\hline & {$[0,0,5,8,6,0]$} & {$[0,0,1,0,4,0]$} & {$[0,0,0,0,2,0]$} & {$[0,0,4,8,0,0]$} & {$[0,0,0,0,0,0]$} \\
\hline \multirow[t]{2}{*}{ Zenith TX $2 \ddagger$} & $11(4)$ & $8(3)$ & $3(1)$ & $0(0)$ & $0(0)$ \\
\hline & {$[0,0,2,2,5,2]$} & {$[0,0,2,2,3,1]$} & {$[0,0,0,0,2,1]$} & {$[0,0,0,0,0,0]$} & {$[0,0,0,0,0,0]$} \\
\hline \multirow[t]{2}{*}{ Zenith TX $1 \ddagger$} & $6(2)$ & $3(1)$ & $1(0)$ & $2(1)$ & $0(0)$ \\
\hline & {$[0,0,0,2,0,4]$} & {$[0,0,0,0,0,3]$} & {$[0,0,0,0,0,1]$} & {$[0,0,0,2,0,0]$} & {$[0,0,0,0,0,0]$} \\
\hline
\end{tabular}

Values are presented as n (\%), [Z0, Z1, Z2, Z3, Z4, Z5]. *Gore Medical, Flagstaff, Ariz. †Medtronic, Santa Rosa, Calif. ł̦Cook, Bloomington, Ind.

TABLE E2. Patient demographic characteristics

\begin{tabular}{|c|c|c|c|c|c|c|}
\hline Characteristic & $\begin{array}{c}\text { Total } \\
(\mathbf{n}=\mathbf{2 2 3}) \\
\end{array}$ & $\begin{array}{c}\text { Aneurysm group } \\
(\mathrm{n}=101)\end{array}$ & $\begin{array}{l}\text { Dissection group } \\
(\mathbf{n}=\mathbf{5 1}) \\
\end{array}$ & $\begin{array}{c}\text { Traumatic group } \\
(\mathbf{n}=\mathbf{5 9})\end{array}$ & $\begin{array}{c}\text { Septic group } \\
(\mathrm{n}=12)\end{array}$ & $P$ value \\
\hline Men & $179(80)$ & $82(81)$ & $42(82)$ & $47(80)$ & $5(62)$ & $<.001$ \\
\hline Mean age (y) & $62.7 \pm 17.9$ & $71.0 \pm 12.5$ & $66.3 \pm 10.4$ & $43.2 \pm 17.2$ & $74.1 \pm 12.5$ & $<.001$ \\
\hline Hypertension & $143(64)$ & $79(78)$ & $46(90)$ & $8(14)$ & $10(83)$ & $<.001$ \\
\hline Smokers & $62(28)$ & $36(36)$ & $12(24)$ & $11(19)$ & $3(25)$ & $<.001$ \\
\hline Diabetes & $17(8)$ & $10(10)$ & $3(6)$ & $4(7)$ & $0(0)$ & .95 \\
\hline Dyslipidemia & $95(43)$ & $53(52)$ & $26(51)$ & $10(17)$ & $6(50)$ & $<.001$ \\
\hline Coronary artery disease & $58(26)$ & $40(40)$ & $10(20)$ & $3(5)$ & $5(42)$ & $<.001$ \\
\hline Coronary artery revascularization & $26(12)$ & $18(18)$ & $3(6)$ & $3(5)$ & $2(17)$ & .08 \\
\hline Coronary artery bypass & $6(3)$ & $5(5)$ & $0(0)$ & $1(2)$ & $0(0)$ & .63 \\
\hline Ejection function $<60 \%$ & $32(14)$ & $25(24)$ & $4(8)$ & $1(2)$ & $3(25)$ & $<.001$ \\
\hline Arrhythmia & $31(14)$ & $19(19)$ & $8(16)$ & $2(3)$ & $2(17)$ & $<.001$ \\
\hline Pacemaker & $4(2)$ & $3(3)$ & $0(0)$ & $0(0)$ & $1(8)$ & .19 \\
\hline Stroke & $19(9)$ & $12(12)$ & $5(10)$ & $0(0)$ & $2(17)$ & .02 \\
\hline Peripheral arterial disease & $34(15)$ & $27(27)$ & $5(10)$ & $1(2)$ & $1(8)$ & $<.001$ \\
\hline Renal insufficiency & $28(13)$ & $21(21)$ & $2(4)$ & $2(3)$ & $3(25)$ & $<.001$ \\
\hline Dialysis & $5(2)$ & $5(5)$ & $0(0)$ & $0(0)$ & $0(0)$ & .42 \\
\hline COPD & $38(17)$ & $29(28)$ & $6(12)$ & $1(2)$ & $2(17)$ & $<.001$ \\
\hline $\begin{array}{l}\text { Restrictive respiratory } \\
\text { insufficiency }\end{array}$ & $4(2)$ & $2(2)$ & $2(4)$ & $0(0)$ & $0(0)$ & .22 \\
\hline Neoplasia & $34(15)$ & $18(18)$ & $9(18)$ & $2(3)$ & $5(42)$ & .02 \\
\hline Previous aortic surgery & $48(22)$ & $32(32)$ & $15(29)$ & $0(0)$ & $1(8)$ & $<.001$ \\
\hline Valvular heart replacement & $11(5)$ & $2(2)$ & $9(18)$ & $0(0)$ & $0(0)$ & $<.001$ \\
\hline Ascending aorta & $13(6)$ & $2(2)$ & $11(22)$ & $0(0)$ & $0(0)$ & $<.001$ \\
\hline Descending aorta & $12(5)$ & $11(11)$ & $0(0)$ & $0(0)$ & $1(8)$ & .013 \\
\hline Abdominal aorta & $29(13)$ & $23(23)$ & $5(10)$ & $0(0)$ & $1(8)$ & $<.001$ \\
\hline \multicolumn{7}{|l|}{ ASA score } \\
\hline$\geq 3$ & $187(84)$ & $83(82)$ & $45(88)$ & $47(80)$ & $12(100)$ & .67 \\
\hline 3 & $86(39)$ & $39(39)$ & $26(51)$ & $20(34)$ & $1(8)$ & \\
\hline 4 & $83(37)$ & $37(37)$ & $17(33)$ & $22(37)$ & $7(58)$ & \\
\hline 5 & $18(8)$ & $7(7)$ & $2(4)$ & $5(8)$ & $4(33)$ & \\
\hline
\end{tabular}

Values are presented as $\mathrm{n}(\%)$ or mean \pm standard derivation. COPD, Chronic obstructive pulmonary disease; ASA, American Society of Anesthesiologists. 
TABLE E3. Distribution of distal landing zone

\begin{tabular}{|c|c|c|c|c|c|}
\hline Zone & $\begin{array}{c}\text { Total } \\
(\mathrm{n}=\mathbf{2 2 3})\end{array}$ & $\begin{array}{l}\text { Aneurysm group } \\
\quad(\mathbf{n}=101)\end{array}$ & $\begin{array}{l}\text { Dissection group } \\
\quad(\mathbf{n}=\mathbf{5 1})\end{array}$ & $\begin{array}{l}\text { Traumatic group } \\
\qquad(\mathbf{n}=\mathbf{5 9})\end{array}$ & $\begin{array}{l}\text { Septic group } \\
\quad(n=12)\end{array}$ \\
\hline Zone 4 & $17(8)$ & $59(58.4)$ & $42(82.4)$ & 57 (96.6) & $10(83.3)$ \\
\hline Emergent & $6(2.7)$ & $19(18.8)$ & $24(47.1)$ & $48(81.4)$ & $10(83.3)$ \\
\hline Elective & $11(4.9)$ & $40(39.6)$ & $18(35.3)$ & $9(15.3)$ & $0(0)$ \\
\hline Zone 5 & $17(8)$ & $35(34.7)$ & 8 (15.7) & $2(3.4)$ & $2(16.7)$ \\
\hline Emergent & $6(2.7)$ & $10(9.9)$ & $1(2.0)$ & $2(3.4)$ & $2(16.7)$ \\
\hline Elective & $11(4.9)$ & $25(24.8)$ & 7 (13.7) & $0(0)$ & $0(0)$ \\
\hline Zone 6 & $59(26)$ & $3(3.0)$ & $0(0)$ & $0(0)$ & $0(0)$ \\
\hline Emergent & $29(13)$ & $2(2.0)$ & $0(0)$ & $0(0)$ & $0(0)$ \\
\hline Elective & $30(13.4)$ & $1(1.0)$ & $0(0)$ & $0(0)$ & $0(0)$ \\
\hline Zone 7 & $81(36)$ & $2(2.0)$ & $0(0)$ & $0(0)$ & $0(0)$ \\
\hline Emergent & $63(28.2)$ & $1(1.0)$ & $0(0)$ & $0(0)$ & $0(0)$ \\
\hline Elective & $18(8.1)$ & $1(1.0)$ & $0(0)$ & $0(0)$ & $0(0)$ \\
\hline Zone 8 & $33(15)$ & $0(0)$ & $0(0)$ & $0(0)$ & $0(0)$ \\
\hline Emergent & $11(4.9)$ & $0(0)$ & $0(0)$ & $0(0)$ & $0(0)$ \\
\hline Elective & $22(9.9)$ & $0(0)$ & $0(0)$ & $0(0)$ & $0(0)$ \\
\hline Zone 9 & $16(7)$ & $2(2.0)$ & $1(2.0)$ & $0(0)$ & $0(0)$ \\
\hline Emergent & $6(2.7)$ & $0(0)$ & $1(2.0)$ & $0(0)$ & $0(0)$ \\
\hline Elective & $10(4.5)$ & $2(2.0)$ & $0(0)$ & $0(0)$ & $0(0)$ \\
\hline
\end{tabular}

Values are presented as $\mathrm{n}(\%)$.

TABLE E4. Nonfatal intraoperative complications

\begin{tabular}{lr}
\hline \multicolumn{1}{c}{ Complication } & Result \\
\hline Iliofemoral access trauma & $11(4.9)$ \\
Endovascular treatment & $7(3.1)$ \\
Open surgery treatment & $4(1.8)$ \\
Endograft migration & $19(8.5)$ \\
Distal migration & $8(3.6)$ \\
Supra-aortic trunks covering & $11(4.9)$ \\
Manual balloon traction & $3(1.3)$ \\
Endovascular treatment & $5(2.2)$ \\
Open surgery treatment & $2(0.9)$ \\
Surveillance & $1(0.4)$ \\
Intraoperative rupture & $1(0.4)$ \\
\hline Values are presented as $\mathrm{n}(\%)$. &
\end{tabular}


TABLE E5. Postoperative cause of death

\begin{tabular}{|c|c|c|c|c|c|}
\hline Cause of death & $\begin{array}{l}\text { All patients } \\
(\mathbf{n}=\mathbf{2 2 3})\end{array}$ & $\begin{array}{l}\text { Aneurysm group } \\
(\mathbf{n}=\mathbf{1 0 1})\end{array}$ & $\begin{array}{l}\text { Dissection group } \\
\quad(\mathbf{n}=\mathbf{5 1})\end{array}$ & $\begin{array}{c}\text { Traumatic group } \\
\quad(\mathbf{n}=\mathbf{5 9})\end{array}$ & $\begin{array}{l}\text { Septic group } \\
\quad(\mathbf{n}=12)\end{array}$ \\
\hline Multisystem organ failure & $12(5.4)$ & $8(7.9)$ & $4(7.8)$ & $0(0)$ & $0(0)$ \\
\hline Cardiac & $5(2.2)$ & $4(4.0)$ & $0(0)$ & $0(0)$ & $1(8.3)$ \\
\hline Respiratory & $3(1.3)$ & $3(3.0)$ & $0(0)$ & $0(0)$ & $0(0)$ \\
\hline Bowel ischemia & $3(1.3)$ & $2(2.0)$ & $1(2.0)$ & $0(0)$ & $0(0)$ \\
\hline Neurologic & $2(0.9)$ & $1(1.0)$ & $0(0)$ & $1(1.7)$ & $0(0)$ \\
\hline Retrograde aortic dissection & $1(0.4)$ & $1(1.0)$ & $0(0)$ & $0(0)$ & $0(0)$ \\
\hline
\end{tabular}

Values are presented as $\mathrm{n}(\%)$.

TABLE E6. Postoperative moderate to severe complications

\begin{tabular}{|c|c|c|c|c|c|}
\hline Complication & $\begin{array}{c}\text { All patients } \\
(\mathbf{n}=\mathbf{2 2 3})\end{array}$ & $\begin{array}{l}\text { Aneurysm group } \\
\quad(n=101)\end{array}$ & $\begin{array}{l}\text { Dissection group } \\
\quad(\mathbf{n}=\mathbf{5 1})\end{array}$ & $\begin{array}{c}\text { Traumatic group } \\
\quad(\mathbf{n}=\mathbf{5 9}) \\
\end{array}$ & $\begin{array}{c}\text { Septic grouI } \\
(\mathbf{n}=12)\end{array}$ \\
\hline None & $161(72.2)$ & $65(64.4)$ & $36(70.6)$ & $51(86.4)$ & $9(75)$ \\
\hline Respiratory & $26(11.7)$ & $10(9.9)$ & $4(7.8)$ & $8(13.6)$ & $2(16.7)$ \\
\hline Hemodialysis & $20(9.0)$ & $11(10.9)$ & $6(11.8)$ & $3(5.1)$ & $0(0)$ \\
\hline Cardiac & $15(6.7)$ & $8(7.9)$ & $2(3.9)$ & $3(5.1)$ & $2(16.7)$ \\
\hline Stroke & $10(4.5)$ & $4(4.0)$ & $5(9.8)$ & $1(1.7)$ & $0(0)$ \\
\hline Wound & $7(3.1)$ & $4(4.0)$ & $3(5.9)$ & $0(0)$ & $0(0)$ \\
\hline Spinal cord ischemia & $6(2.7)$ & $4(4.0)$ & $2(3.9)$ & $0(0)$ & $0(0)$ \\
\hline Bowel ischemia & $6(2.7)$ & $3(3.0)$ & $3(5.9)$ & $0(0)$ & $0(0)$ \\
\hline Retrograde aortic dissection & $6(2.7)$ & $5(5.0)$ & $1(2.0)$ & $0(0)$ & $0(0)$ \\
\hline Limb ischemia & $5(2.2)$ & $3(3.0)$ & $2(3.9)$ & $0(0)$ & $0(0)$ \\
\hline Hemothorax & $4(1.8)$ & $2(2.0)$ & $2(3.9)$ & $0(0)$ & $0(0)$ \\
\hline Endograft collapse & $1(0.4)$ & $0(0)$ & $0(0)$ & $1(1.7)$ & $0(0)$ \\
\hline
\end{tabular}

Values are presented as $\mathrm{n}(\%)$.

TABLE E7. Postoperative type of early reintervention

\begin{tabular}{|c|c|c|c|c|c|}
\hline Type of reintervention & $\begin{array}{c}\text { All patients } \\
(\mathbf{n}=\mathbf{2 2 3})\end{array}$ & $\begin{array}{l}\text { Aneurysm group } \\
\quad(\mathbf{n}=101)\end{array}$ & $\begin{array}{l}\text { Dissection group } \\
\quad(\mathbf{n}=\mathbf{5 1})\end{array}$ & $\begin{array}{c}\text { Traumatic group } \\
(\mathbf{n}=\mathbf{5 9})\end{array}$ & $\begin{array}{c}\text { Septic group } \\
(\mathrm{n}=12)\end{array}$ \\
\hline Aortic & $12(5.4)$ & $7(6.9)$ & $3(5.9)$ & $2(3.4)$ & $0(0)$ \\
\hline Endovascular & $7(3.1)$ & $3(3.0)$ & $2(3.9)$ & $2(3.4)$ & $0(0)$ \\
\hline Open surgery & $5(2.2)$ & $4(4.0)$ & $1(2.0)$ & $0(0)$ & $0(0)$ \\
\hline Supra aortic trunks & $4(1.8)$ & $2(2.0)$ & $1(2.0)$ & $0(0)$ & $1(8.3)$ \\
\hline Endovascular & $2(0.9)$ & $1(1.0)$ & $0(0)$ & $0(0)$ & $1(8.3)$ \\
\hline Open surgery & $2(0.9)$ & $1(1.0)$ & $1(2.0)$ & $0(0)$ & $0(0)$ \\
\hline Wound & $4(1.8)$ & $3(3.0)$ & $1(2.0)$ & $0(0)$ & $0(0)$ \\
\hline Bowel resection & $4(1.8)$ & $3(3.0)$ & $1(2.0)$ & $0(0)$ & $0(0)$ \\
\hline Hemothorax & $4(1.8)$ & $2(2.0)$ & $2(3.9)$ & $0(0)$ & $0(0)$ \\
\hline Cervical hematoma & $3(1.3)$ & $1(1.0)$ & $2(3.9)$ & $0(0)$ & $0(0)$ \\
\hline Minor amputation & $1(0.4)$ & $0(0)$ & $1(2.0)$ & $0(0)$ & $0(0)$ \\
\hline
\end{tabular}

Values are presented as $\mathrm{n}(\%)$. 
TABLE E8. Late cause of death

\begin{tabular}{|c|c|c|c|c|c|}
\hline Cause of death & $\begin{array}{l}\text { All patients } \\
(\mathbf{n}=197)\end{array}$ & $\begin{array}{l}\text { Aneurysm group } \\
\quad(n=82)\end{array}$ & $\begin{array}{l}\text { Dissection group } \\
\quad(n=46)\end{array}$ & $\begin{array}{l}\text { Traumatic group } \\
(\mathbf{n}=\mathbf{5 8})\end{array}$ & $\begin{array}{l}\text { Septic group } \\
\quad(\mathbf{n}=11)\end{array}$ \\
\hline Neoplasia & $9(4.6)$ & $5(6.1)$ & $1(2.2)$ & $0(0)$ & $3(27.3)$ \\
\hline Respiratory & $3(1.5)$ & $2(2.4)$ & $1(2.2)$ & $0(0)$ & $0(0)$ \\
\hline Endograft infection & $3(1.5)$ & $1(1.2)$ & $0(0)$ & $0(0)$ & $2(18.2)$ \\
\hline Retrograde aortic dissection & $2(1.0)$ & $1(1.2)$ & $1(2.2)$ & $0(0)$ & $0(0)$ \\
\hline Gastrointestinal & $2(1.0)$ & $1(1.2)$ & $1(2.2)$ & $0(0)$ & $0(0)$ \\
\hline Stroke & $1(0.5)$ & $1(1.2)$ & $0(0)$ & $0(0)$ & $0(0)$ \\
\hline Acute limb ischemia & $1(0.5)$ & $1(1.2)$ & $0(0)$ & $0(0)$ & $0(0)$ \\
\hline AAA rupture & $1(0.5)$ & $1(1.2)$ & $0(0)$ & $0(0)$ & $0(0)$ \\
\hline TAA rupture & $1(0.5)$ & $1(1.2)$ & $0(0)$ & $0(0)$ & $0(0)$ \\
\hline Cardiac & $1(0.5)$ & $0(0)$ & $1(2.2)$ & $0(0)$ & $0(0)$ \\
\hline MSOF & $1(0.5)$ & $0(0)$ & $1(2.2)$ & $0(0)$ & $0(0)$ \\
\hline Unknown & $2(1.0)$ & $2(2.4)$ & $0(0)$ & $0(0)$ & $0(0)$ \\
\hline
\end{tabular}

Values are presented as $\mathrm{n}(\%)$. AAA, Abdominal aortic aneurysm; TAA, thoracic aortic aneurysm; $M S O F$, multisystem organ failure. 